\title{
Using Relationship-Focused Group Therapy to Target Insecure Attachment as a Barrier to Sex Offense-Specific Treatment: A Pilot Study
}

\author{
Jerry L. Jennings ${ }^{1}$, Shan Jumper ${ }^{2}$, Christopher Baglio ${ }^{1}$ \\ ${ }^{1}$ Liberty Healthcare Corporation, Bala Cynwyd, PA, USA \\ ${ }^{2}$ Illinois Treatment and Detention Facility, Rushville, IL, USA \\ Email: jerry.jennings@libertyhealth.com
}

How to cite this paper: Jennings, J. L., Jumper, S., \& Baglio, C. (2021). Using Relationship-Focused Group Therapy to Target Insecure Attachment as a Barrier to Sex Offense-Specific Treatment: A Pilot Study. Open Journal of Social Sciences, 9, 386-408. https://doi.org/10.4236/jss.2021.92026

Received: January 13, 2021

Accepted: February 22, 2021

Published: February 25, 2021

\section{Copyright $\odot 2021$ by author(s) and} Scientific Research Publishing Inc. This work is licensed under the Creative Commons Attribution-NonCommercial International License (CC BY-NC 4.0). http://creativecommons.org/licenses/by-nc/4.0/ c) (i) (8) Open Access

\begin{abstract}
Given the high rates of insecure attachment and adverse childhood experiences in men who sexually abuse, this pilot study examined whether an eight-month course of relationship-focused group therapy could make a positive impact on insecure attachment as a barrier to treatment engagement. Fifty subjects were identified by treatment teams as failing to make progress and/or engage meaningfully in a facility-based, sex offense-specific treatment program for civilly committed men who sexually offend. The subjects were assigned to five simultaneous new "motivational" groups that applied interpersonal-focused group therapy that emphasized interpersonal relating rather than criminogenic offense behavior. Participants showed significant improvement on the Secure Attachment subscale and three Secure items of the Relationship Styles Questionnaire (RSQ), suggesting that group-centered group promoted positive gains in interpersonal attachment, particularly in terms of reduced loneliness, reduced fear of acceptance, and greater comfort in depending on others. Participants assessed as having made good progress in the pilot treatment also showed significant improvement on a fourth Secure subscale item pertaining to greater ease with emotional closeness. Results further suggested that groups with better overall ratings of therapeutic climate using the Group Climate Questionnaire (GCQ) generally showed more movement toward secure attachment.
\end{abstract}

\section{Keywords}

Sex Offense-Specific Treatment, Group Therapy, Sexual Abuse, Attachment 


\section{Introduction}

\subsection{Use of Group Therapy in Sex Offense-Specific Treatment}

Historically, group-based treatment has been the primary modality of treatment in the field of sex offense-specific treatment (SOST) since its inception in the 1950s. As observed in their clinical and empirical review of group therapy in the SOST field, Jennings and Deming (2016) contrasted two major approaches to the use of group therapy in the field of SOST: The first approach was psychoanalytic in orientation and appreciated that the social/peer influence of group therapy could do something that individual therapy could not: break through denial and shame by providing an opportunity for social acceptance and meaningful relationships that promoted prosocial values over deviancy. Then, in the 1980s, the field of SOST was revolutionized by the second approach, which focused on cognitive behavioral treatment (CBT) and relapse prevention, and the situation reversed. For the next 25 years, the SOST field expanded dramatically and was dominated by CBT, which was typically applied in psychoeducational group formats and focused heavily on cognitive restructuring and sex offense behavior. But this predominant CBT approach largely neglected the therapeutic benefits that can be gained through the interpersonal relations of the group modality itself. With the new century, however, the SOST field appears to have "rediscovered" the value of group therapy in three regards:

\subsubsection{New Emphasis on Interpersonal Relating in SOST Groups}

In a seminal article published in 2003, Jennings and Sawyer (2003) challenged the field of SOST to rethink its use of the group modality to improve treatment effectiveness. They argued that psychoeducational CBT groups could be invigorated and improved by making greater use of group cohesion and group dynamics. As distinguished from CBT interventions that focused on thinking errors and offense patterns of the individuals within the group, Jennings and Sawyer advocated for more group-focused interventions that engaged all group members, facilitated interaction and interpersonal relating, and used cohesion and peer support to motivate change. In a series of publications, they continued to develop this "group-centered group" approach, which emphasized interpersonal relating and emotional expression within the structure and safety of a cohesive group (Jennings \& Deming, 2013; Sawyer \& Jennings, 2014, 2016; Jennings \& Jumper, 2019).

\subsubsection{Renewed Appreciation of Therapeutic Factors and Group Climate}

During the same period, the SOST field also began to shift from an exclusive CBT focus on offense behavior and relapse prevention to a more holistic view of sexual abuse and its treatment. Emerging SOST research in the 2000s brought a renewed appreciation of the therapeutic alliance, a new strengths-based emphasis on motivation and positive approach goals (Marshall \& Hollin, 2015), and a more holistic "Good Lives" approach that fostered prosocial values and pursuits that promote long-term desistance (Yates, Prescott, \& Ward, 2010). As summarized in empirical reviews by Marshall and Burton (2010), Marshall, Burton and 
Marshall (2013), and Jennings and Deming (2016), the research showed that SOST effectiveness is directly influenced by therapist characteristics, the quality of the therapeutic relationship, the clients' level of motivation and engagement, and-of specific concern to this study-the therapeutic climate in SOST groups. In particular, at least ten studies showed that the therapeutic qualities of the SOST group therapist-warmth, empathy, encouragement, guidance, and a non-confrontational approach-accounted for $30 \%$ to $60 \%$ of treatment change (Marshall et al., 2002, 2003; Harkins \& Beech, 2007; Marshall \& Burton, 2010; Marshall et al. 2013). Likewise, five studies by Levenson and colleagues (Levenson \& Macgowan, 2004; Levenson et al., 2009; Levenson \& Prescott, 2009; Levenson et al., 2010; Levenson et al., 2014a, 2014b) found that clients in both secure inpatient and outpatient SOST overwhelmingly rated "confrontation among the group members" as not helpful, while Drapeau (2005) and Drapeau et al. (2004) found that child molesters disengaged from therapists who were confrontational.

Moreover, landmark empirical studies of SOST group climate by Beech and colleagues (Beech \& Fordham, 1997; Beech \& Hamilton-Giachritsis, 2005; Harkins, Beech, \& Thornton, 2012) showed that group cohesiveness and group expressiveness should be emphasized as "essential preconditions" for positive behavioral change in men who sexually abuse. Similarly, Taft, Murphy, King, Musser \& DeDeyn (2003) found that positive therapist alliance ratings and greater group cohesion predicted lower levels of physical and psychological abuse after 6-months of treatment and were the strongest predictors of outcome for partner violent men.

\subsubsection{Appreciation of the Impact of Trauma and Attachment Deficits}

In recent years, the SOST field has looked more closely at treatment in terms of a growing appreciation for the prevalence and impact of early childhood adversity and trauma among youth and men who sexually abuse (Grady, Levenson, \& Bolder, 2017; Yoder, Grady, Brown, \& Dillard, 2019). In a widely cited study using the Adverse Childhood Experience scale, Levenson, Willis and Prescott (2014b) found that men who sexually abuse had experienced three times the rate of child sexual abuse, twice the rate of physical abuse, 13 times the rate of verbal abuse, and four times the rate of emotional neglect and broken homes. Further, as reviewed by Sawyer \& Jennings (2016), an extensive research literature shows that males who sexually abuse have higher rates of insecure attachment than non-sexual offenders and normal populations, and higher rates of attachment-related deficiencies, such as isolation, loneliness, intimacy deficits, and toxic father relationships.

\subsection{The Attachment Theory of Sexual Offending}

As first articulated by Marshall (1989), attachment theory has been proposed to explain the link between childhood adversity and sexual offending and has been one of the most influential ideas in the field of SOST. Marshall hypothesized that adverse and traumatic experiences of childhood, particularly the inability to form 
trusting and secure relationships with one's caregivers in early life, contributes to the development of sexually abusive behavior. "Insecure attachment" to one's caretakers can impair both self-confidence and trust-in-others, and thereby harms the individual's ability or desire to engage in developmentally appropriate relationships as adolescents and later as adults. Lacking the experience, skills and values needed to seek out and establish close relationships, the youth becomes increasingly isolated, lonely and alienated, which sets the stage for inappropriate and aggressive sexual behavior, deviance and sexual abuse (Figure 1). In essence, the insecurely attached male engages in sexually abusive or developmentally inappropriate sexual behaviors in a maladaptive attempt to fulfill his intimacy and self-esteem needs and/or to express his negative and angry feelings about himself and his social alienation (Ward, Hudson, Marshall, \& Siegert, 1995).

Marshall's attachment theory offered an etiology that could explain the development of different types of sexual deviance, abuse, and aggression from a common root cause. For example, fearing rejection from peers, one insecure individual might turn to young children as an inappropriate way to meet intimacy needs and overcome loneliness, while another might turn to rape to forcibly fulfill his needs for human bonding and affirm his masculine competence.

\subsection{Insecure Attachment as a Barrier to Treatment Engagement}

If insecure attachment can become a barrier to forming healthy adult sexual relationships, then it may also function as a barrier to engaging in sustained treatment to change sexually abusive behavior. Despite the extensive evidence for pervasive attachment deficits and adverse childhood experiences for men who sexually abuse, however, there has been little attention to addressing insecure attachment as a primary treatment target or, more specifically, as a means of reducing a common barrier to sustained engagement in CBT-oriented SOST. Indeed, insecure attachment could be barrier to treatment because research shows that it negatively impacts both the therapeutic alliance and the perception of a therapeutic climate, both of which are deemed "essential preconditions" for effective SOST treatment (Marshall, 2005; Marshall et al., 2013).

A meta-analysis of 17 non-offender attachment studies showed that secure attachment is strongly related to greater therapeutic alliance, while insecure attachment is related to poorer therapeutic relationships (Diener \& Monroe, 2001). It has also been shown that positive perceptions of therapeutic climate promote positive treatment outcomes with both non-sex offenders (Gillaspy et al. 2002;

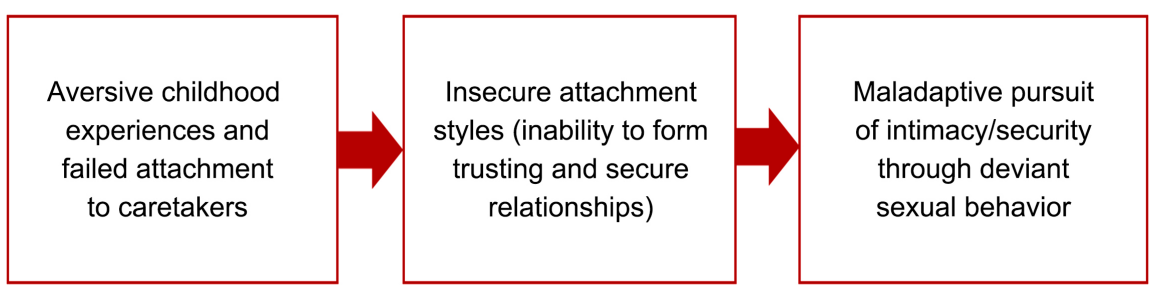

Figure 1. Attachment theory of sexual offending. 
Martin, Garske, \& Davis, 2000), and men who sexually offend (Beech \& Fordham, 1997; Beech \& Hamilton-Giachritsis, 2005; Marshall \& Burton, 2010). Research with non-sex offenders has shown that the client's attachment style directly impacts their perception of the therapeutic climate in both individual and group therapy (Dozier, 1990; Eames \& Roth, 2000; Goldman \& Anderson, 2007; Korfmacher, Adam, Ogawa, \& Egeland, 1997; Mallinckrodt, Gantt, \& Coble, 1995; Parish \& Eagle, 2003).

This relationship between attachment style and therapeutic climate was observed in a group treatment study of 277 incarcerated men with sex offenses, which used the Moos' Group Environment Scale (Garbutt \& Hocken, 2014; Garbutt \& Palmer, 2015). Of the ten subscale dimensions of group process, men with "secure attachment style" had positive perceptions of Leader Support, Task Orientation, Order and Organization, and Self-Discovery in their SOST groups. In contrast, men with "dismissive/avoidant style" showed only positive perceptions of Leader Support and Task Orientation, while "pre-occupied/anxious" men had negative perceptions of Leader Support, and "fearful/avoidant" men were averse to the more spontaneous emotional expressiveness that characterizes Self-Discovery.

These results suggest that men who sexually abuse may have differential responses to group treatment based on their attachment styles (Sawyer \& Jennings, 2016). Thus, for example, men with a preoccupied/anxious style of insecure attachment will specifically struggle with the essential precondition of forming a therapeutic relationship, while those with fearful-avoidant style will specifically struggle with the essential precondition of "emotional expressiveness."

The idea of targeting attachment deficits as barriers to treatment engagement is also encouraged by research showing that group therapy can facilitate more secure attachment in non-offending populations (Keating, Tasca, Gick, Ritchie, Balfour, \& Bissada, 2014; Kilmann, Urbaniak, \& Parnell, 2006; Maxwell, Tasca, Ritchie, Balfour, \& Bissada, 2014; Tasca, Balfour, Ritchie, \& Bissada, 2007). Within the SOST field, Grady, Swett and Shields (2016) found that men of all attachment styles showed significant improvement in attachment and relationship measures, showing that group therapy can foster healthier attachment. Further, Reavis, Looman, Franco, and Rojas (2013) recommend that SOST programs should emphasize role of early childhood trauma in self-regulation and attachment, while Grady, Looman, and Abracen (2019) suggest attachment-based interventions in SOST.

In view of the above research, this pilot study sought to determine if an interpersonal group intervention could make a positive effect on attachment and thereby reduce a barrier to treatment engagement. As part of an initiative to motivate more meaningful and sustained engagement in sex offense-specific treatment, the pilot study started five simultaneous "motivational" therapy groups in a pre-post quasi-experimental design with no control group. Three research questions were posed:

Question \#1: Improved attachment promotes treatment engagement. If 
improved attachment can reduce a barrier to SOST treatment, individuals assessed as improved and ready to "graduate" from the pilot group treatment will show more improvement in secure attachment than those who do not graduate.

Question \#2: Group therapy can improve secure attachment. Group therapy with a focus on relationships and interactions within the group (rather than an exclusive focus on offense issues) will promote positive changes in secure attachment style (and concomitant reductions in insecure attachment style).

Question \#3: Better group climate promotes more secure attachment. Groups with good therapeutic climate (characterized by high engagement, high cohesion, low conflict, low avoidance, and high group therapist alignment) should promote more positive changes in secure attachment than groups with poor therapeutic climate.

\section{Method}

\subsection{Participants}

The sample consisted of 50 adult males with convictions for extremely violent and/or repeated sexual offending, who were found eligible for civil commitment as "sexually violent persons" in a secure intensive treatment facility in Illinois. As a collective group, the residents had been incarcerated and/or institutionalized for long periods of time, even decades for some. The subjects were selected from a pool of individuals who had been previously involved in the main sex offense-specific treatment program within the secure facility but had stopped making progress and/or withdrawn from treatment. Common reasons for non-engagement in treatment included poor participation, failure to complete homework, low motivation to change, refusal to attend treatment, and causing behavioral disruptions to treatment groups.

Five motivational therapy groups, called "Power to Change" groups, were formed and started at the same time. Assignment to the five groups was not purely random, but it was guided by an effort to mix residents from various treatment teams with different therapists from other teams. In this way, every group contained co-therapists and group members who were mostly (not always) unfamiliar with each other. Participation in the twice-weekly Power to Change groups was voluntary and the men had free choice to complete the questionnaires, which were administered on an anonymous basis once each month.

All the participating group therapists were masters or doctoral level clinicians with at least one year of experience in sex offense-specific treatment. The study was approved by the Interdisciplinary Research Review Committee of the Illinois Office of Mental Health.

\subsection{Measures}

\subsubsection{Recommendation for "Graduation"}

Each pair of group therapists, in conjunction with the clinicians on the client's designated treatment team, monitored the progress of the group members and, 
when applicable, they conjointly made a determination that an individual was ready to "graduate" from the interpersonally-focused group in order to reenter the main SOST program. The recommendation for graduation was a global assessment of progress based on the quality of the individual's participation in the Power to Change group, but also considered his behavior in the residential milieu. Thus, a positive assessment of progress could be attenuated by contradictory evidence of anti-social behavior occurring outside the group in the facility.

\subsubsection{Pre- and Post-Treatment Attachment}

The authors administered the 17-item, self-report Relationship Style Questionnaire (RSQ) as the measure of secure/insecure attachment (Griffin \& Bartholomew, 1994). The participants completed the RSQ at the beginning of the study and eight months later. Item scores are averaged to yield four subscales that correspond to four attachment styles: Secure, Dismissive/Avoidant, Fearful/Avoidant, and Preoccupied/Anxious. Of the 50 men in the sample, 37 completed the preand post-treatment RSQ, and 13 declined. The plan to administer the second "post-test" RSQ in month 8 was based on research on the RSQ that shows moderate stability over an 8-month test re-test period (Scharfe \& Bartholomew, 1994) and to allow at least one-half year of treatment as reasonable time for change to occur (Fjeldstad, 2019).

\subsubsection{Monthly Ratings of Group Therapeutic Climate}

Once each month, the participants evaluated the therapeutic climate of their respective groups by completing the Group Climate Questionnaire (GCQ). The GCQ is the most commonly used measure of group process in the group psychotherapy literature (Johnson et al., 2006). With just 12 items, the GCQ is brief and easy to use. Item scores are averaged to yield three subscale scores corresponding to three dimensions of group climate: Engagement is the extent to which members feel connected to each other and actively participate in group process. It is roughly equivalent to cohesion, which is considered the foremost therapeutic factor in group therapy (Yalom \& Leszcz, 2020; Burlingame, McClendon, \& Yang, 2018). Conflict is the degree of conflict, hostility, and tension in the group. Avoidance is the degree to which group members avoid looking at important issues, both personally and interpersonally.

\subsubsection{Group Therapist Alignment}

The two co-therapists of each group completed the GCQ on a monthly basis along with the group members. Simple correlations were calculated between the GCQ item ratings by the co-therapists and their group members as a rough global measure of "alignment" in their perceptions of group climate. Scores ranged from a high correlation suggesting strong alignment $(r=0.86)$ to a low correlation suggesting weak alignment $(r=0.13)$.

\subsection{Procedure}

As part of an initiative to motivate more improved engagement for men failing 
to make progress in the main sex offense-specific treatment program, the pilot study started five simultaneous "Power to Change" groups with two co-therapists and about 10 men each. The groups met twice weekly for a period of eight months.

Prior to the pilot study, the group therapists attended two days of training in a model of relationship-focused group therapy for men who sexually abuse as posited by Sawyer and Jennings (2016). The model incorporates empirically-based best practices from the general group therapy literature (Burlingame et al., 2018; Yalom \& Leszcz, 2020) and emphasizes the primacy of establishing a safe, cohesive group climate that encourages interpersonal interaction, bonding, emotional expression, and relating. Stated simply, the group therapists were encouraged to emphasize and promote positive interpersonal relating and cohesion among group members (using group facilitation techniques from the training) rather than focusing explicitly on sexual offending and criminogenic factors (per SOST).

Given that "short-term" group therapy is often defined as 6 months duration and/or 20 sessions and has been shown to be effective with a wide variety of mental disorders (Feldstein, 2019), the pilot study allotted eight months as sufficient time to make the desired positive impact, which was to motivate men to return to the regular sex offense-specific treatment program with enhanced levels of engagement. For example, Tasca, Balfour, Presniak, \& Bissada (2012) showed that six months of attachment-based treatment using both Group Psychodynamic Interpersonal Group Psychotherapy and Cognitive-Behavior Group Therapy could reduce interpersonal problems across eight domains.

By the time of the final administration of the RSQ at month 8, a total of 13 men were "graduated" from their respective Power to Change groups and returned to the regular SOST program, while the others continued as needed in the Power to Change groups. (Note: Group climate continued to be measured for its value as an internal program quality measure, but the study data stopped at month 8.)

\section{Results}

\section{Question 1: Graduates show improvement in secure attachment}

The first research question predicted that graduates would show greater improvement in secure attachment than non-graduates. A 2X2 mixed model ANOVA was performed to determine if there were differences in Relationship Style Questionnaire (RSQ) subscale scores as a factor of either pre- and post-test scores (i.e., initial and final scores) and/or improvement (i.e., graduated vs. did not graduate). No significant main effects were found between graduates and non-graduates for any of the four RSQ subscales or significant interactions for pre- and post-treatment scores.

Although no significant differences were found for any of the four RSQ attachment style subscale scores, significant differences were found for two indi- 
vidual items as presented in Table 1. The ANOVA found a significant main effect by "graduation" for RSQ item \#3; $F(1,35)=5.28, p<0.05)$, with those who graduated reporting higher levels of emotional closeness during the final assessment period $(\mathrm{M}=3.54, \mathrm{SD}=0.88)$ when compared to those who did not graduate $(\mathrm{M}=2.54, \mathrm{SD}=1.35 ; p<0.05)$. No effects over time $(F(1,35)=2.35)$ or interaction effects $(F(1,35)=0.65)$ were observed. A significant difference was also found between graduates and nongraduates for RSQ item \#16 $(F(1,35)=6.70, p$ $<0.05$ ), with those not graduating reporting a greater desire to not depend on others during both initial $(\mathrm{M}=3.50, \mathrm{SD}=1.32)$ and final $(\mathrm{M}=3.70, \mathrm{SD}=1.33)$ administrations when compared with those who graduated (initial $\mathrm{M}=2.54$, $\mathrm{SD}$ $=1.45$; final $\mathrm{M}=2.62, \mathrm{SD}=1.12$ ).

Question \#2: Interpersonal group promotes secure attachment

The second research question predicted that interpersonally-focused group therapy could promote positive changes in secure attachment style (and concomitant reductions in insecure attachment style). Table 2 summarizes the initial and final scores on the RSQ. Nine RSQ items and three subscales showed a change in a positive direction, while seven RSQ items and one subscale showed a change in a negative direction, and two items showed no change. Of note, only three items, all of which contribute to the Secure style subscale, showed salient improvement. Two were statistically significant with a third closely approaching significance $(p<0.051)$. Positive improvement in the composite Secure subscale was also statistically significant. Given that some items are reversed for scoring, the up arrows denote score changes in a positive (desirable) direction and down arrows denote changes in a negative (undesirable) direction.

A dependent-samples t-test compared the initial (pre-treatment) RSQ subscale scores with the post-treatment scores (see Table 3). There was a significant difference in the scores for the initial Secure subscale measure $(\mathrm{M}=3.13, \mathrm{SD}=$ $0.52)$ and final Secure subscale measure following treatment $(\mathrm{M}=2.35, \mathrm{SD}=$ $0.78) ; t(36)=2.36, p<0.05$. Upon examination of the individual items that load on this subscale, two of the five items showed a significant change over time. Study participants reported a decrease in "worry about being alone" from baseline $(\mathrm{M}=$ $3.49, \mathrm{SD}=1.43)$ to month eight $(\mathrm{M}=2.57, \mathrm{SD}=1.39) ; t(36)=3.19, p<0.01$. The greatest amount of reported change was a decrease in the level of "worry about having others accept me" from baseline $(\mathrm{M}=3.90, \mathrm{SD}=1.21)$ to month

Table 1. Significant RSQ item scores by "graduation" and non-graduation.

\begin{tabular}{|c|c|c|c|c|c|c|c|c|}
\hline & \multicolumn{4}{|c|}{ Graduated } & \multicolumn{4}{|c|}{ Did Not Graduate } \\
\hline & \multicolumn{2}{|c|}{ Initial } & \multicolumn{2}{|c|}{ Final } & \multicolumn{2}{|c|}{ Initial } & \multicolumn{2}{|c|}{ Final } \\
\hline & M & $\mathrm{SD}$ & M & SD & M & SD & M & SD \\
\hline \#3. I find it easy to get emotionally close to others. & 3.00 & 1.29 & 3.54 & 0.88 & 2.38 & 1.21 & 2.54 & 1.35 \\
\hline \#16. I prefer not to depend on others. & 2.54 & 1.45 & 2.62 & 1.12 & 3.50 & 1.32 & 3.70 & 1.33 \\
\hline
\end{tabular}

$p<0.05$. 
Table 2. Changes in attachment style before and after group treatment.

\begin{tabular}{|c|c|c|c|c|c|c|}
\hline & \multicolumn{2}{|c|}{ Initial (pre-treatment) } & \multicolumn{2}{|c|}{ Final (post-treatment) } & & \multirow{2}{*}{ t-test } \\
\hline & M & SD & M & SD & & \\
\hline \multicolumn{7}{|l|}{ Secure Attachment Style Items } \\
\hline 7. I worry about being alone. & 3.49 & 1.43 & 2.57 & 1.39 & $\uparrow$ & $3.19^{* *}$ \\
\hline 17. I worry about having others not accept me. & 3.90 & 1.21 & 2.69 & 1.39 & $\uparrow$ & $4.27^{\star * *}$ \\
\hline 8. I am comfortable depending on other people. & 2.28 & 1.11 & 2.72 & 1.19 & $\uparrow$ & $-2.02^{++}$ \\
\hline 3. I find it easy to get emotionally close to others. & 2.59 & 1.26 & 2.89 & 1.29 & $\uparrow$ & -1.36 \\
\hline 10. I am comfortable having other people depend on me. & 3.30 & 1.10 & 3.22 & 1.23 & $\downarrow$ & 0.36 \\
\hline Secure Subscale & 3.12 & 0.53 & 2.56 & 0.92 & $\uparrow$ & $2.36^{*}$ \\
\hline \multicolumn{7}{|l|}{ Dismissive Avoidant Style Items } \\
\hline 5R. I am comfortable without close emotional relationships. & 3.05 & 1.22 & 2.95 & 1.22 & $\uparrow$ & 0.46 \\
\hline 2. It is very important to me to feel independent. & 3.97 & 1.21 & 3.97 & 0.99 & -- & 0.00 \\
\hline 12. It is very important to me to feel self-sufficient. & 3.81 & 1.37 & 4.00 & 0.91 & $\downarrow$ & -0.87 \\
\hline 13. I prefer not to have other people depend on me. & 2.59 & 1.28 & 2.68 & 1.16 & $\downarrow$ & -0.31 \\
\hline 16. I prefer not to depend on others. & 3.17 & 1.44 & 3.31 & 1.35 & $\downarrow$ & -0.65 \\
\hline Dismissive Subscale & 3.30 & 0.82 & 3.38 & 0.69 & $\downarrow$ & -0.67 \\
\hline \multicolumn{7}{|l|}{ Fearful Avoidant Style Items } \\
\hline 1. I find it difficult to depend on other people. & 2.92 & 1.30 & 2.78 & 1.25 & $\uparrow$ & 0.53 \\
\hline 4. I worry that I will be hurt if I allow myself to become too close to others. & 3.03 & 1.40 & 2.70 & 1.33 & $\uparrow$ & 1.46 \\
\hline 14. I am somewhat uncomfortable being close to others. & 2.67 & 1.29 & 2.50 & 1.11 & $\uparrow$ & 0.81 \\
\hline 9. I find it difficult to trust others completely. & 3.29 & 1.27 & 3.29 & 1.25 & -- & 0.00 \\
\hline Fearful subscale & 2.96 & 0.97 & 2.78 & 0.98 & $\uparrow$ & 1.10 \\
\hline \multicolumn{7}{|l|}{ Preoccupied/Anxious Style Items } \\
\hline 5. I am comfortable without close emotional relationships. & 2.95 & 1.22 & 3.03 & 1.24 & $\downarrow$ & -0.34 \\
\hline 11. I worry that others don't value me as much as I value them. & 2.56 & 1.23 & 2.25 & 1.00 & 1 & 1.38 \\
\hline 6. I want to be completely emotionally intimate with others. & 2.46 & 1.22 & 2.62 & 1.01 & $\downarrow$ & -0.80 \\
\hline 15. I find that others are reluctant to get as close as I would like. & 2.22 & 1.11 & 2.30 & 1.02 & $\downarrow$ & -0.52 \\
\hline Preoccupied Subscale & 2.55 & 0.78 & 2.53 & 0.71 & $\uparrow$ & 0.17 \\
\hline
\end{tabular}

${ }^{* * *} p<0.001 ;{ }^{* *} p<0.01{ }^{*} p<0.05 ;{ }^{++}$approaching significance $p<0.051$. 
eight $(\mathrm{M}=2.69, \mathrm{SD}=1.39) ; t(36)=4.27, p<0.001$. In addition, participants reported an increase in being "comfortable depending on others." While not statistically significant, the difference from baseline $(\mathrm{M}=2.28, \mathrm{SD}=1.11)$ to month eight $(M=2.72, \mathrm{SD}=1.19)$ approached significance $(p<0.051)$, showing the study participants demonstrated increased security in this regard. No significant differences were found for any of the three insecure attachment style subscales or items for either the initial or final measure.

Question 3: Good group therapeutic climate promotes more secure attachment

The third research question predicted that groups with better therapeutic climate would have a greater positive impact on secure attachment. A series of one-way analysis of variance comparisons were conducted to test whether there were significant differences across the RSQ subscales as a factor of assigned therapy group. As captured within Table 3, a significant difference was found for the Secure subscale, during the final administration of the RSQ $(F(4,32)=$ $4.87, p<0.01)$. Upon examination of the Tukey post hoc analyses, it was determined that the differences were between the Green group $(\mathrm{M}=3.58, \mathrm{SD}=0.73)$ and the Blue group $(\mathrm{M}=2.35, \mathrm{SD}=0.78 ; p<0.05)$, and the Purple group $(\mathrm{M}=$ $2.11, \mathrm{SD}=0.82 ; p<0.01)$.

This shows that the Green group had significantly better outcomes in secure attachment than the Blue and Purple groups. But did the Green group also have better therapeutic climate than the Blue and Purple groups as predicted? The short answer is yes, but the picture is more complex. Group scores on each GCQ item and subscale are presented in Table 4. There were significant differences among the five therapy groups on every item of the Engaged and Conflict Subscales, but no significant differences on any items of the Avoidance Subscale.

Table 3. Group differences in initial and final attachment style subscale scores.

\begin{tabular}{|c|c|c|c|c|c|c|c|c|c|c|c|}
\hline & \multicolumn{2}{|c|}{ Blue } & \multicolumn{2}{|c|}{ Green } & \multicolumn{2}{|c|}{ Orange } & \multicolumn{2}{|c|}{ Purple } & \multicolumn{2}{|c|}{ Red } & \multirow{2}{*}{ F-Value } \\
\hline & M & SD & M & SD & M & SD & M & SD & M & $\mathrm{SD}$ & \\
\hline Secure - Initial & 3.13 & 0.52 & 3.42 & 0.44 & 2.93 & 0.27 & 2.90 & 0.66 & 3.07 & 0.65 & 1.34 \\
\hline Secure - Final & $2.35 \mathrm{~g}$ & 0.78 & $3.58 \mathrm{bp}$ & 0.73 & 2.60 & 0.31 & $2.11 \mathrm{~g}$ & 0.82 & 3.03 & 1.05 & $4.87^{\star *}$ \\
\hline Fearful - Initil & 3.28 & 0.80 & 2.75 & 1.04 & 2.92 & 0.79 & 2.96 & 1.28 & 2.92 & 1.06 & 0.32 \\
\hline Fearful - Final & 3.06 & 0.78 & 2.80 & 0.90 & 2.67 & 1.16 & 2.64 & 1.14 & 2.63 & 1.23 & 0.24 \\
\hline Preoccupied - Initial & 2.59 & 0.92 & 2.35 & 0.83 & 2.33 & 0.72 & 2.39 & 0.32 & 3.25 & 0.71 & 1.71 \\
\hline Preoccupied - Final & 2.53 & 0.45 & 2.53 & 0.88 & 2.79 & 0.64 & 2.14 & 0.70 & 2.75 & 0.76 & 0.86 \\
\hline Dismissive - Initial & 3.48 & 0.67 & 3.32 & 0.94 & 3.27 & 0.73 & 2.91 & 1.08 & 3.50 & 0.60 & 0.54 \\
\hline Dismissive - Final & 3.53 & 0.59 & 3.54 & 0.75 & 3.23 & 0.74 & 3.23 & 0.96 & 3.27 & 0.37 & 0.39 \\
\hline
\end{tabular}

${ }^{* *} p<0.01 ;{ }^{\mathrm{pg}} p<0.01 ;{ }^{\mathrm{bg}} p<0.05$. 
Table 4. Group differences in group therapeutic climate.

\begin{tabular}{|c|c|c|c|c|c|c|c|c|c|c|c|}
\hline & \multicolumn{2}{|c|}{ Blue } & \multicolumn{2}{|c|}{ Green } & \multicolumn{2}{|c|}{ Orange } & \multicolumn{2}{|c|}{ Purple } & \multicolumn{2}{|c|}{ Red } & \multirow{2}{*}{$F$-Value } \\
\hline & M & $\mathrm{SD}$ & M & $\mathrm{SD}$ & M & SD & M & SD & M & $\mathrm{SD}$ & \\
\hline Engaged Subscale & $3.06_{\mathrm{go}}$ & 0.79 & $4.41_{\mathrm{bpr}}$ & 0.75 & $4.26_{\mathrm{b}}$ & 0.67 & $3.24 \mathrm{~g}$ & 0.57 & $3.16_{\mathrm{g}}$ & 0.79 & $6.41^{* *}$ \\
\hline $\begin{array}{l}\text { \#1. The members liked and cared about } \\
\text { each other. }\end{array}$ & $2.87_{\mathrm{go}}$ & 1.04 & $4.33_{\mathrm{bpr}}$ & 1.07 & $4.32 \mathrm{br}$ & 0.49 & $3.00 \mathrm{~g}$ & 0.47 & $2.76_{\mathrm{go}}$ & 0.89 & $6.30^{* *}$ \\
\hline $\begin{array}{l}\text { \#2. The members tried to understand why they } \\
\text { do the things they do, tried to reason it out. }\end{array}$ & $2.81_{\mathrm{go}}$ & 1.08 & $4.42_{\mathrm{bpr}}$ & 0.97 & $4.25 \mathrm{~b}$ & 0.76 & $3.07 \mathrm{~g}$ & 0.54 & $3.00_{\mathrm{g}}$ & 0.91 & $5.75^{* *}$ \\
\hline $\begin{array}{l}\text { \#4. The members felt what was happening was } \\
\text { important and there was a sense of participation. }\end{array}$ & $3.28 \mathrm{~g}$ & 0.96 & $4.67 \mathrm{bpr}$ & 0.71 & 4.31 & 0.73 & $3.35 \mathrm{~g}$ & 0.74 & $3.25 \mathrm{~g}$ & 0.80 & $5.78^{\star \star}$ \\
\hline $\begin{array}{l}\text { \#8. The members challenged and confronted } \\
\text { each other in their efforts to sort things out. }\end{array}$ & 3.11 & 0.51 & 4.02 & 1.12 & 4.35 & 0.68 & 3.41 & 0.94 & 3.16 & 0.57 & $3.02^{*}$ \\
\hline $\begin{array}{l}\text { \#11. The members revealed sensitive personal } \\
\text { information or feelings. }\end{array}$ & $3.26 \mathrm{~g}$ & 0.87 & $4.61_{\mathrm{bp}}$ & 0.79 & 4.06 & 1.16 & $3.34 \mathrm{~g}$ & 0.80 & 3.61 & 0.89 & $3.44^{*}$ \\
\hline Conflict Subscale & $2.28 \mathrm{go}$ & 0.90 & $0.69 \mathrm{br}$ & 0.47 & $0.92 \mathrm{~b}$ & 0.56 & 1.47 & 0.62 & $1.89 \mathrm{~g}$ & 0.86 & $7.38^{\star * *}$ \\
\hline $\begin{array}{l}\text { \#6. There was friction and anger between } \\
\text { the members. }\end{array}$ & 2.28 gop & 0.93 & $0.76 \mathrm{~b}$ & 0.49 & $0.95 \mathrm{~b}$ & 0.46 & $1.07 \mathrm{~b}$ & 0.67 & 1.69 & 0.93 & $6.16^{* *}$ \\
\hline $\begin{array}{l}\text { \#7. The members were distant and } \\
\text { withdrawn from each other. }\end{array}$ & $2.21_{\mathrm{go}}$ & 0.87 & $0.84 \mathrm{~b}$ & 0.90 & $0.59 \mathrm{~b}$ & 0.59 & 1.20 & 0.77 & 1.83 & 0.93 & $4.91^{* *}$ \\
\hline $\begin{array}{l}\text { \#10. The members rejected and } \\
\text { distrusted each other. }\end{array}$ & $1.98_{\mathrm{go}}$ & 0.92 & $0.58 \mathrm{~b}$ & 0.65 & $0.73_{\mathrm{b}}$ & 0.48 & 1.09 & 0.65 & 1.57 & 0.97 & $4.76^{* *}$ \\
\hline $\begin{array}{l}\# 12 . \text { The members appeared tense } \\
\text { and anxious. }\end{array}$ & $2.47 \mathrm{~g}$ & 1.14 & $0.58 \mathrm{bpr}$ & 0.40 & 1.40 & 0.82 & $1.98 \mathrm{~g}$ & 1.33 & $2.44 \mathrm{~g}$ & 0.75 & $6.34^{\star *}$ \\
\hline Avoidance Subscale & 2.58 & 0.56 & 2.36 & 0.66 & 2.50 & 0.88 & 2.42 & 0.63 & 2.40 & 0.25 & 0.15 \\
\hline $\begin{array}{l}\text { \#3. The members avoided looking at important } \\
\text { issues going on between themselves. }\end{array}$ & 2.26 & 0.77 & 1.48 & 1.46 & 2.06 & 0.98 & 1.69 & 0.82 & 2.46 & 0.54 & 1.20 \\
\hline $\begin{array}{l}\text { \#5. The members depended upon the group } \\
\text { leader(s) for direction. }\end{array}$ & 2.48 & 0.84 & 1.64 & 1.00 & 2.20 & 1.17 & 2.34 & 1.02 & 1.94 & 0.49 & 1.10 \\
\hline $\begin{array}{l}\text { \#9. The members appeared to do things the way } \\
\text { they thought would be acceptable to the group. }\end{array}$ & 3.04 & 0.70 & 4.03 & 1.20 & 3.22 & 0.80 & 3.24 & 0.87 & 2.79 & 0.73 & 2.21 \\
\hline
\end{tabular}

${ }^{*} p<0.05 ;{ }^{* *} p<0.01 ;{ }^{* * *} p<0.001$.

The next analysis looked closer at the Group Climate Questionnaire (GCQ) data to examine the relationship between therapeutic climate of the five groups and the two outcome measures of attachment and graduation. Since all the groups had very similar Avoidance subscale scores, this was eliminated from the analysis. The groups were rank ordered using the Engagement and Conflict subscales and two other measures of therapeutic climate. First, based on the face validity of CGQ item \#1- "The members liked and cared about each other" -this item was used as a measure of group cohesion. Second, the correlations between the GCQ ratings of the group therapists and the ratings of their group members were used as a measure of "therapist alignment." 
As shown in Table 5, the five groups were ranked ordered from "Excellent" to "Very Poor" (i.e., from best to worst) based on the four measures of group therapeutic climate. The Green group clearly appeared to have the best climate, ranking first in engagement, conflict, and cohesion, and second in therapist alignment - and its climate was rated as "excellent." The Orange group also had "very good" climate, ranking first in therapist alignment and second in engagement, conflict, and cohesion. The Purple group ranked third in all four measures-for a rating of "good." The Red group ranked fourth in three of four categories-for a rating of "poor", while the Blue group ranked fifth in three of four categories-for a rating of "very poor."

Although there appeared to be a clear rank ordering of the therapeutic climate of the five groups, the outcomes were not so clearly aligned. In terms of graduation rates, there was a rough correspondence between the quality of therapeutic climate and outcomes. The Orange group with a very good climate graduated $50 \%$ of its members, while the Green group with excellent climate graduated $40 \%$. In turn, the Purple group with good climate graduated $29 \%$ and the Blue group with the worst climate had the worst graduation rate at $13 \%$. But the pattern is broken by the Red group, which had a poor therapeutic climate, but shared the highest rate of graduation at $50 \%$.

Table 5. Rank ordering of groups by therapeutic climate and outcomes.

\begin{tabular}{|c|c|c|c|c|c|c|}
\hline Climate Measures & Green & Orange & Purple & Red & Blue & All \\
\hline \multirow{2}{*}{${ }^{\star}$ Engagement Subscale } & $1^{\text {st }}$ & $2^{\text {nd }}$ & $3^{\text {rd }}$ & $4^{\text {th }}$ & $5^{\text {th }}$ & \\
\hline & 4.35 & 4.26 & 3.31 & 3.09 & 2.69 & 3.52 \\
\hline \multirow{2}{*}{${ }^{\star}$ Conflict Subscale } & $1^{\text {st }}$ & $2^{\text {nd }}$ & $3^{\text {rd }}$ & $4^{\text {th }}$ & $5^{\text {th }}$ & \\
\hline & 0.61 & 0.78 & 1.23 & 1.72 & 2.65 & 1.42 \\
\hline \multirow{2}{*}{ Cohesion (GCQ item \#1 avg) } & $1^{\text {st }}$ & $2^{\text {nd }}$ & $3^{\text {rd }}$ & $5^{\text {th }}$ & $4^{\text {th }}$ & \\
\hline & 4.33 & 4.32 & 3.0 & 2.76 & 2.87 & 3.51 \\
\hline \multirow{2}{*}{ Therapist alignment } & $2^{\text {nd }}$ & $1^{\text {st }}$ & $3^{\text {rd }}$ & $4^{\text {th }}$ & $5^{\text {th }}$ & \\
\hline & $r=0.64$ & $r=0.86$ & $\mathrm{r}=0.49$ & $r=0.24$ & $r=0.13$ & $\mathrm{r}=0.47$ \\
\hline Overall group therapeutic climate & Excellent & Very Good & Good & Poor & Very Poor & \\
\hline \multicolumn{7}{|l|}{ Outcome Measures } \\
\hline \multirow{2}{*}{ \% did well enough to "Graduate" } & $2^{\text {nd }}$ & $1^{\mathrm{st}}$ & $3^{\text {rd }}$ & $1^{\text {st }}$ & $5^{\text {th }}$ & \\
\hline & $40 \%$ & $50 \%$ & $29 \%$ & $50 \%$ & $13 \%$ & $35 \%$ \\
\hline \multicolumn{7}{|l|}{ Secure Subscale items } \\
\hline \multirow{2}{*}{${ }^{\star}$ Worry about being alone (\#7) } & $5^{\text {th }}$ & $2^{\text {nd }}$ & $2^{\text {nd }}$ & $4^{\text {th }}$ & $1^{\text {st }}$ & \\
\hline & $20 \%$ & $63 \%$ & $63 \%$ & $33 \%$ & $86 \%$ & $51 \%$ \\
\hline \multirow{2}{*}{${ }^{*}$ Worry of being accepted (\#17) } & $3^{\text {rd }}$ & $1^{\text {st }}$ & $1^{\text {st }}$ & $5^{\text {th }}$ & $2^{\text {nd }}$ & \\
\hline & $50 \%$ & $88 \%$ & $88 \%$ & $33 \%$ & $71 \%$ & $62 \%$ \\
\hline \multirow{2}{*}{${ }^{*}$ Comfortable with being depended on by others (\#10) } & $1^{\text {st }}$ & $3^{\text {rd }}$ & $3^{\text {rd }}$ & $4^{\text {th }}$ & $5^{\text {th }}$ & \\
\hline & $50 \%$ & $38 \%$ & $38 \%$ & $33 \%$ & $29 \%$ & $38 \%$ \\
\hline
\end{tabular}

Key: ${ }^{*}=$ items that were statistically significant at $p<0.051$ or better; Green $=1^{\text {st }}$ or $2^{\text {nd }}$ ranking Red $=4^{\text {th }}$ or $5^{\text {th }}$ ranking. 
In terms of the percentage of men who improved on the three Secure subscale items, the pattern is mixed for therapeutic climate. With regard to Secure item \#10 ("being comfortable having others depend on me"), the rank ordering of groups by climate corresponds to the rate of improvement. Thus, the Green group with best climate has the highest percentage of improvement at $50 \%$, the Orange group with second best climate had the second best improvement at $38 \%$, and so on, to the Blue group with the worst climate and worst rate at $29 \%$. But this pattern was very different for Secure items \#7 ("worry about being alone") and \#17 ("worry about acceptance"). Here the Blue group with the worst climate shared very high percentages of positive change along with the Orange and Purple groups, which had very good and good climates respectively. At the same time, the Red group with poor climate and the Green group with excellent climate had the lowest percentages of men improve on items \#7 and \#17.

Given these inconsistencies, one more analysis was conducted to see whether some groups might have had a higher proportion of more "secure" men from the beginning, which would influence their ratings of therapeutic climate. Based on each individual's highest score on four RSQ subscales, each subject was assigned a predominant attachment style, which yielded the following breakdown: $38 \%$ secure, $38 \%$ dismissive/avoidant, $16 \%$ fearful/avoidant, and $8 \%$ preoccupied/anxious. It is notable that the predominant attachment style at the start remained the same for all of the men at the end of eight months.

\section{Discussion}

\subsection{Primary Conclusions Based on Rationale}

In conclusion, the pilot study showed support for the value of relationship-focused group therapy in promoting more secure attachment in men who sexually abuse, but it was inconclusive in showing that groups with the best therapeutic climate have a greater positive effect on secure attachment than groups with poor or mediocre climate.

Regarding Research Question \#1, men who were assessed as having improved sufficiently to "graduate" from the pilot treatment groups reported significantly increased levels of "emotional closeness" on RSQ Secure item \#3 ("easy to get emotionally close") than those who did not graduate. As one of the five items on the secure subscale, this suggests that interpersonally-focused group treatment may have improved secure attachment for the graduates. On the other hand, both graduates and non-graduates showed a slight worsening in their preference to avoid "depending on others" (item \#16), which is a Dismissive/Avoidant insecure attachment style characteristic, although the graduates are significantly less avoidant in this regard at the beginning and at the end of the treatment period.

Regarding Research Question \#2, group-centered group treatment was able to achieve statistically significant improvements on the RSQ secure attachment subscale and specific secure item scores (although there were no concomitant 
reductions in the insecure attachment scores). Improvements were observed in reduced worry about being alone (item \#7), reduced fear of acceptance (item $\# 17$ ), and increased comfort in depending on others (item \#8). More than half of the participants (55\%) showed an improvement on at least two of these three secure items; while only $8 \%$ showed a worsening on at least two of the three, and $38 \%$ showed either no change or a mix of improvement and worsening.

With regard to Research Question \#3, which predicted a direct relationship between the quality of the group therapeutic climate and improvements in secure attachment, the results were mixed and more complex. Two groups (Orange and Green) showed statistically significant higher levels of Engagement (on all 5 GCQ items) and statistically significantly lower levels of Conflict (on all 4 GCQ items) compared with the other three groups. The Orange and Green groups appeared to have the best therapeutic climate, cohesion, and therapist alignment and both showed improvements in secure attachment. But the Blue group, which had the poorest therapeutic climate, matched the Orange group in showing improvements overall. Finally, every group showed improvements in secure attachment except the Red group, which had medium levels of therapeutic climate. Thus, a clear and direct relationship between the quality of the group therapeutic climate and improvements in secure attachment was not observed.

Examination of differences in the percentage of "secure" members among the groups as a potential mediating variable also appeared to make little difference in ratings of therapeutic climate, graduation, or improved secure scores. The five groups each had a roughly similar mix of Secure, Dismissive/Avoidant and Preoccupied/Anxious style members. The Blue group, however, was unique in having three members with Fearful/Avoidant style (50\%) while other groups had just one or none. Since men with Fearful/Avoidant style tend to have exaggerated perceptions of threat and are dubious of positive experiences (Sawyer \& Jennings, 2016), this could help explain why the Blue group had the lowest member ratings of therapeutic climate, yet showed excellent outcomes.

\subsection{Methodological and Other Limitations of the Study}

There are several important limitations of this study that should be considered in evaluating its strength and implications for practice, beginning with the research methodology. First, the research design lacked any control group or waitlist group, which weakens the determination that the intervention-relationship-focused group treatment-actually caused or contributed to the observed increases in Secure attachment style scores.

A second limitation is the exploratory nature of the pilot study. It was never intended to be a formal research study. The Power to Change groups began as a quality improvement initiative to motivate more meaningful engagement in the primary sex offender-specific treatment program. For this reason, the GCQ was used as a monthly measure of the therapeutic climate of the groups, while the RSQ was added to see if differing insecure attachment styles might impact 
treatment responsiveness and vice versa. In fact, the Power to Change groups were so well received that the SOST program continues to use them as a motivational intervention four years later. As an exploratory research study, however, this study lacked any clearly defined hypotheses for testing, which increases the risk of chance findings.

Further, as an exploratory pilot study, there was no effort to control potentially confounding subject variables, such as length of time in treatment, dosage/amount of previous treatment, and current status in the stages/phases of the SOST program. Future research could reduce this limitation through random assignment and/or by matching clients on subject characteristics, such as PCL-R scores, and distributing them evenly among the groups.

A third limiting factor is the small sample size and its unique characteristics. Given that the groups were limited to 10 or less individuals, the small sample size raises concerns about effect size and whether the data is normally distributed. Further, generalization of results is limited by the fact that the subjects were civilly committed men who have been incarcerated and institutionalized for long periods of time and who have previously failed to progress in traditional CBT-oriented sex offense-specific treatment. With a high average of 26.8 on the Psychopathy Checklist Revised (PCL-R), the men in the study were decidedly more anti-social than other populations.

A fourth limiting factor was the lack of random assignment to the five groups. Despite efforts to mix members from the various treatment teams to create the new therapy groups, it was inescapable that the group therapists would have some direct familiarity with some of the members from previous encounters in the treatment facility and could be biased.

A fifth limiting factor was the potential for therapist bias and social desirability. The improvements in self-ratings of secure attachment could be nothing more than attempts by the men to look good by answering the questionnaire items in the socially desirable way. If so, the men who graduated may have been better at discerning and displaying the in-group behavior and attitudes desired by the group therapists, which would also make them more likeable to the therapists who assessed their progress. Moreover, the therapists could be biased in their assessments because the foremost measure of the success of their groups was graduation.

Three factors, however, suggest that the men's questionnaire responses were honest. First, the men's responses to both the GCQ and RSQ were anonymous so that no individual could gain favor from the co-therapists by scoring in the socially desired manner. Second, the individual pre- and post-test attachment scores were quite consistent in that not a single man changed in his predominant attachment style eight months later. Third, the determination of improvement to graduation was not based entirely on the group therapists' assessments, but encompassed a global assessment of each individual's behavior in the secure residential milieu by his designated treatment team, which often did not include the 
group therapist(s). Thus, a positive assessment of progress could be attenuated by contradictory evidence of anti-social behavior occurring outside the group in the facility.

A sixth limitation may be the use of self-report as the primary measure of attachment. As a self-report instrument, the Relationship Styles Questionnaire is not as strong as the Adult Attachment Interview, which is a quasi-clinical, semi-structured in-depth interview that takes an hour to administer (Reis, 2015). But even if some men over-estimated their secure attachment in order to look good (38\% scored themselves in a way that showed "secure" attachment style), the RSQ remains a valuable measure of changes in the individual's perceptions of himself in his relationships to others.

Finally, and perhaps most importantly, the fidelity of the group-centered treatment is a potential limiting factor. The pilot study was designed for men who were assessed by their treating clinicians as unmotivated, resistant, or otherwise "stuck" in the mainstream sex offender-specific treatment program, which was predominantly cognitive-behavioral with a focus on Self-Regulation and the Good Lives Model. The guiding idea was to set aside the usual focus on offense-specific issues and instead use these newly formed groups to facilitate interpersonal relating among the men in hopes of improving insecure attachment deficits as a barrier to treatment engagement and behavioral change. Given that there was no set curriculum or guidelines for how the therapists co-facilitated their groups to achieve the desired goals, it is hard to say that every group of men received the same or equivalent treatment intervention. Further, there was no measure or monitoring of how consistently the pairs of co-therapists were applying the relationship-focused group intervention.

Thus, the positive effects might be attributable to the experience of a well-run "general" therapy process group. Perhaps the men lacked prior success in the CBT-oriented psychoeducational SOST groups because there was less intention or focus on doing good group work. Or perhaps the group experience of feeling heard and supported, and being free to relate and bond with peers was a powerful and potent new experience for men who had been incarcerated for years and had only known CBT-oriented psychoeducational groups. In any case, the twice weekly Power to Change groups were the only treatment received for eight months and appear to have had a positive impact, even if the intervention was simply "good" group therapy.

\subsection{Practical Implications}

Practical research challenges: The lack of randomized control and the simplicity of this study is a stark reminder of the difficulties of conducting the "gold standard" of randomized controlled trials (RCTs) in real-world criminal justice settings - especially if it is being done by non-academic clinicians who lack the time, funding, or statistical research sophistication to do it rigorously. The SOST subfield has a number of unique practical and ethical barriers to conducting re- 
search. For example, if the RCT design requires a "no treatment" control group, it potentially creates risk for sexual abuse to occur for those left "untreated." Also, many clients with a history of sexual offending cannot freely "volunteer" for treatment because of criminal justice mandates. Barriers such as these have contributed to the specific paucity of RCTs and the overall absence of evidence-based practices in the SOST field (Deming \& Jennings, 2020).

Conducting research on the effects of group treatment can be even more complex. The authors had a rare and timely opportunity to assemble and study a sample of 50 individuals (treatment-resistant ones at that) who could be started in five parallel treatment groups for an 8-month period. Pure randomization and sample matching was an impossible luxury. Given the less-than-ideal design, the data analyses were conducted entirely at the individual level, which ignores the potential effects of nested/dependent data in groups. Accordingly, one reviewer recommended the use of a "three-level multilevel growth model for nested change data" that is specific to group therapy research (Tasca, Illing, Joyce \& Ogrodniczuk, 2009). This advice might be ideal, but it would be tantamount to throwing away rare data from a one-time, real-world opportunity that cannot be regenerated.

Implications for psychopathy treatment. In a related research study, Jennings and Jumper (2021) reviewed 27 studies, five meta-analyses, and one systematic review of outcomes following some sort of group treatment for men high in psychopathy. They found that treatment effect was poor or negative when studies focused only on recidivism outcomes. But when studies presented measures of treatment responsiveness, men high in psychopathy actually appear to respond very positively to group-based treatment. Jennings and Jumper (2021) argued that psychopathy is an interpersonal disorder and that group therapy is an interpersonal treatment that can be effective with severe psychopathy. Instead of segregating men who are high in psychopathy into their own groups and/or putting greater emphasis on criminogenic issues in those groups, they suggest that "interpersonally-focused" group therapy with healthier low or non-psychopathy peers can provide an interpersonal growth experience that can open opportunities for prosocial learning and change for men high in psychopathy.

Implications for SOST and traditional CBT group approaches: This study has strong implications for mainstream approaches to the treatment of individuals who sexually abuse. As noted in the introduction, psychoeducational groups have been the most common modality used in the field for decades. Most such groups are structured, apply cognitive-behavioral concepts and language, and focus on criminogenic needs and offense patterns. While CBT should continue to be used as a mainstream, evidence-based practice in SOST, this study suggests that interpersonally-focused group therapy can both bolster and supplement established CBT approaches. It can bolster CBT psychoeducational groups by enlivening the learning environment with interpersonal interaction and by creating 
a cohesive and supportive community that encourages participation and growth. But it can also supplement treatment for individuals who are struggling with, or resistant to, traditional CBT-oriented treatment that focuses heavily on offense-related thinking and behavior.

Insecure attachment as a treatment target. As noted earlier, Marshall's (1989) attachment theory of sexual offending has generated a wealth of research showing that men who sexually abuse have higher rates of attachment-related deficiencies, such as isolation, loneliness, intimacy deficits, and adverse childhood experiences. But efforts to directly treat insecure attachment-as a barrier to traditional treatment, or even as an end in itself-are only beginning to emerge. This pilot study contributes to that beginning by showing that a course of relatively short (eight months) and mildly intensive (twice weekly) interpersonally-focused group treatment can have a significant impact on attachment deficits.

If insecure attachment is prevalent among men and youth who sexually abuse, and if attachment styles directly impact both the quality of the therapeutic relationship and perceptions of the therapeutic climate, then insecure attachment may be a common barrier to engaging and benefiting from treatment. If insecure attachment issues are a common barrier, then it may be valuable to assess and address these issues as targets in sex offense-specific treatment and we believe that relationship-focused group therapy is an ideal modality for doing so. Further research will be needed to see whether this interpersonal group approach can be a useful way of increasing individual responsivity in this field of treatment.

\section{Acknowledgements}

The authors are responsible for the integrity of the data, accuracy of the data analyses, and have made effort to avoid inflating statistically significant results. The authors have no financial interests to disclose.

\section{Conflicts of Interest}

The authors declare no conflicts of interest regarding the publication of this paper.

\section{References}

Beech A., \& Fordham, A. (1997). Therapeutic Climate of Sexual Offender Treatment Programs. Sexual Abuse, 9, 219-237. https://doi.org/10.1177/107906329700900306

Beech, A., \& Hamilton-Giachritsis, C. (2005). Relationship between Therapeutic Climate \& Treatment Outcome in Group-Based Sexual Offender Treatment Programs. Sexual Abuse, 17, 127-140. https://doi.org/10.1177/107906320501700204

Burlingame, G., McClendon, D., \& Yang, C. (2018). Cohesion in Group Therapy: A Meta-Analysis. Psychotherapy, 55, 384-398. https://doi.org/10.1037/pst0000173

Deming, A., \& Jennings, J. (2020). The Absence of Evidence-Based Practices (EBPs) in the Treatment of Sexual Abusers: Recommendations for Moving toward the Use of a True 
EBP Model. Sexual Abuse, 32, 679-705. https://doi.org/10.1177/1079063219843897

Diener, M., \& Monroe, J. (2001). The Relationship between Adult Attachment Style and Therapeutic Alliance in Individual Psychotherapy: A Meta-Analytic Review. Psychotherapy, 48, 237-248. https://doi.org/10.1037/a0022425

Dozier, M. (1990). Attachment Organization and Treatment Use for Adults with Serious Psychopathological Disorders. Development and Psychopathology, 2, 47-60. https://doi.org/10.1017/S0954579400000584

Drapeau, M. (2005). Research on the Processes Involved in Treating Sexual Offenders. Sexual Abuse, 17, 117-125. https://doi.org/10.1177/107906320501700203

Drapeau, M., Körner, C., Brunet, L., \& Granger, L. (2004). Treatment at La Macaza Clinic: A Qualitative Study of the Sexual Offenders' Perspective. Canadian Journal of Criminology and Criminal Justice, 46, 27-44. https://doi.org/10.3138/cjccj.46.1.27

Eames, V., \& Roth, A. (2000). Patient Attachment Orientation and the Early Working Alliance: A Study of Patient and Therapist Reports of Alliance Quality and Ruptures. Psychotherapy Research, 10, 421-434. https://doi.org/10.1093/ptr/10.4.421

Fjeldstad, A. (2019). The Role of Treatment Duration in Psychodynamic Group Therapy: A Randomized Clinical Trial of Short-Term and Long-Term Group Analytic Psychotherapy. Dissertation, Oslo: University of Oslo.

Garbutt, K., \& Hocken, K. (2014). Treatment Implications of Sex Offenders' Attachment Styles. Paper presented at the 33rd Annual Research and Treatment Conference of the Association for the Treatment of Sexual Abusers, San Diego, 31 October 2014.

Garbutt, K., \& Palmer, E. (2015). Client Attachment and the Perceived Environment in Sexual Offender Treatment. Unpublished manuscript.

Gillaspy, J., Wright, A., Campbell, C., Stokes, S., \& Adinoff, B. (2002). Group Alliance and Cohesion as Predictors of Drug and Alcohol Abuse Treatment Outcomes. Psychotherapy Research, 12, 213-229. https://doi.org/10.1093/ptr/12.2.213

Goldman, G., \& Anderson, T. (2007). Quality of Object Relations and Security of Attachment as Predictors of Therapeutic Alliance. Journal of Counseling Psychology, 54, 111-117. https://doi.org/10.1037/0022-0167.54.2.111

Grady, M., Levenson, J., \& Bolder, T. (2017). Linking Adverse Childhood Effects and Attachment: A Theory of Etiology for Sexual Offending. Trauma, Violence, \& Abuse, 18, 433-444. https://doi.org/10.1177/1524838015627147

Grady, M., Looman, J., \& Abracen, J. (2019). Childhood Abuse, Attachment, and Psychopathy among Individuals Who Commit Sexual Offenses. Sexual Addiction \& Compulsivity, 26, 77-102. https://doi.org/10.1080/10720162.2019.1620660

Grady, M., Swett, L., \& Shields, J. (2016). The Impact of a Sex Offender Treatment Programme on the Attachment Styles of Incarcerated Male Sexual Offenders. Journal of Sexual Aggression, 22, 123-136. https://doi.org/10.1080/13552600.2014.894148

Griffin, D., \& Bartholomew, K. (1994). The Metaphysics of Measurement: The Case of Adult Attachment. In K. Bartholomew, \& D. Perlman (Eds.), Advances in Personal Relationships: Attachment Processes in Adult Relationships (pp. 17-52). London: Jessica Kingsley.

Harkins, L., \& Beech, A. (2007). A Review of the Factors That Can Influence the Effectiveness of Sexual Offender Treatment: Risk, Need, Responsibility, and Process Issues. Aggression and Violent Behavior, 12, 615-627.

https://doi.org/10.1016/j.avb.2006.10.006

Harkins, L., Beech, A., \& Thornton, D. (2012). The Influence of Risk and Psychopathy on the Therapeutic Climate in Sex Offender Treatment. Sexual Abuse, 25, 103-122. 
https://doi.org/10.1177/1079063212443384

Jennings, J., \& Deming, A. (2013). Effectively Utilizing the "Behavioral" in Cognitive-Behavioral Group Therapy of Sex Offenders. International Journal of Behavioral Consultation \& Therapy, 8, 7-13. https://doi.org/10.1037/h0100968

Jennings, J., \& Deming, A. (2016). Review of the Empirical and Clinical Support for Group Therapy Specific to Sexual Abusers. Sexual Abuse, 29, 731-764. https://doi.org/10.1177/1079063215618376

Jennings, J., \& Jumper, S. (2019). Using Good Groups to Attain Good Lives. Ten Techniques for Enhancing the Effectiveness of Group Therapy in the GLM. ATSA Forum, 31 , $\# 2$.

Jennings, J., \& Jumper, S. (2021, in press). Group Therapy Interventions and Psychopathy: An Interpersonal Perspective. In J. Vitale (Ed.). Complexity of Psychopathy. New York: Springer.

Jennings, J., \& Sawyer, S. (2003). Principles and Techniques for Maximizing the Effectiveness of Group Therapy with Sex Offenders. Sexual Abuse, 15, 251-267. https://doi.org/10.1177/107906320301500403

Johnson, J., Pulsipher, D., Ferrin, S., Burlingame, G., Davies, R., \& Gleave, R. (2006). Measuring Group Processes: A Comparison of the GCQ and CCI. Group Dynamics: Theory, Research, and Practice, 10, 136-145. https://doi.org/10.1037/1089-2699.10.2.136

Keating, L., Tasca, G., Gick, M., Ritchie, K., Balfour, L., \& Bissada, H. (2014). Change in Attachment to the Therapy Group Generalizes to Change in Individual Attachment among Women with Binge Eating Disorder. Psychotherapy, 51, 78-87. https://doi.org/10.1037/a0031099

Kilmann, P., Urbaniak, G., \& Parnell, M. (2006). Effects of Attachment-Focused versus Relationship Skills-Focused Interventions for College Students with Insecure Attachment Patterns. Attachment and Human Development, 8, 47-62. https://doi.org/10.1080/14616730600585219

Korfmacher, J., Adam, E., Ogawa, J., \& Egeland, B. (1997). Adult Attachment Implications for the Therapeutic Process in a Home Visitation Intervention. Applied Developmental Science, 1, 43-52. https://doi.org/10.1207/s1532480xads0101 5

Levenson, J., \& Macgowan, M. (2004). Engagement, Denial, and Treatment Progress among Sex Offenders in Group Therapy. Sexual Abuse, 16, 49-63. https://doi.org/10.1177/107906320401600104

Levenson, J., \& Prescott, D. (2009b). Treatment Experiences of Civilly Committed Sex Offenders: A Consumer Satisfaction Survey. Sexual Abuse, 21, 6-20. https://doi.org/10.1177/1079063208325205

Levenson, J., Macgowan, M., Morin, J., \& Cotter, L. (2009a). Perceptions of Sex Offenders about Treatment: Satisfaction \& Engagement in Group Therapy. Sexual Abuse, 21, 35-56. https://doi.org/10.1177/1079063208326072

Levenson, J., Prescott, D., \& D’Amora, D. (2010). Sex Offender Treatment. Consumer Satisfaction and Engagement in Therapy. International Journal of Offender Therapy and Comparative Criminology, 54, 307-326. https://doi.org/10.1177/0306624X08328752

Levenson, J., Prescott, D., \& Jumper, S. (2014a). A Consumer Satisfaction Survey of Civilly Committed Sex Offenders in Illinois. International Journal of Offender Therapy and Comparative Criminology, 58, 474-495. https://doi.org/10.1177/0306624X12472956

Levenson, J., Willis, G., \& Prescott, D. (2014b). Adverse Childhood Experiences in Lives of Male Sex Offenders: Implications for Trauma-Informed Care. Sexual Abuse, 28, 340-359. 


\section{https://doi.org/10.1177/1079063214535819}

Mallinckrodt, B., Gantt, D., \& Coble, H. (1995). Attachment Patterns in Psychotherapy. Development of the Client Attachment to Therapist Scale. Journal of Counseling Psychology, 42, 307-317. https://doi.org/10.1037/0022-0167.42.3.307

Marshall, W. (1989). Intimacy, Loneliness and Sexual Offenders. Behaviour Research and Therapy, 27, 491-504. https://doi.org/10.1016/0005-7967(89)90083-1

Marshall, W. (2005). Therapist Style in Sexual Offender Treatment: Influence on Indices of Change. Sexual Abuse, 17, 109-116. https://doi.org/10.1177/107906320501700202

Marshall, W., \& Burton, S. (2010). The Importance of Group Processes in Offender Treatment. Aggression and Violent Behavior, 15, 141-149. https://doi.org/10.1016/j.avb.2009.08.008

Marshall, W., \& Hollin, C. (2015). Historical Developments in Sex Offender Treatment. Journal of Sexual Aggression, 21, 125-135. https://doi.org/10.1080/13552600.2014.980339

Marshall, W., Burton, D., \& Marshall, L. (2013). Features of Treatment Delivery and Group Processes That Maximize the Effects of Offender Programs. In J. Wood, \& T. Gannon (Eds.), Crime and Crime Reduction: The Importance of Group Processes (pp. 159-174). New York: Routledge.

Marshall, W., Fernandez, Y., Serran, G., Mulloy, R., Thornton, D., Mann, R., \& Anderson, D. (2003). Process Variables in the Treatment of Sexual Offenders: A Review of the Relevant Literature. Aggression and Violent Behavior, 8, 205-234. https://doi.org/10.1016/S1359-1789(01)00065-9

Marshall, W., Serran, G., Moulden, H., Mulloy, R., Fernandez, Y., Mann, R., \& Thornton, D. (2002). Therapist Features in Sexual Offender Treatment: Their Reliable Identification and Influence on Behavior Change. Clinical Psychology and Psychotherapy, 9, 395-405. https://doi.org/10.1002/cpp.335

Martin, M., Garske, J., \& Davis, M. (2000). Relation of the Therapeutic Alliance with Outcome and Other Variables. A Meta-Analytic Review. Journal of Counseling and Clinical Psychology, 68, 438-450. https://doi.org/10.1037/0022-006X.68.3.438

Maxwell, H., Tasca, G., Ritchie, K., Balfour, L., \& Bissada, H. (2014). Change in Attachment Insecurity Is Related to Improved Outcomes 1-Year Post Group Therapy in Women with Binge Eating Disorder. Psychotherapy, 51, 57-65. https://doi.org/10.1037/a0031100

Parish, M., \& Eagle, M. (2003). Attachment to the Therapist. Psychoanalytic Psychology, 20, 271-286. https://doi.org/10.1037/0736-9735.20.2.271

Reavis, J., Looman, J., Franco, K., \& Rojas, B. (2013). Adverse Childhood Experiences and Adult Criminality: How Long Must We Live before We Possess Our Own Lives? The Permanente Journal, 17, 44-48. https://doi.org/10.7812/TPP/12-072

Reis, M. (2015). Exploring the Attachment Style of Sex Offenders. Dissertation, Birmingham: University of Birmingham.

Sawyer, S., \& Jennings, J. (2014). Facilitating Group-Centered Treatment Groups for Sex Offenders. In M. Carich, \& S. Mussack (Eds.), The Handbook of Sexual Abuser Assessment and Treatment (pp. 125-150). Brandon, VT: Safer Society Press.

Sawyer, S., \& Jennings, J. (2016). Group Therapy with Those Who Sexually Abuse: Engaging the Full Potential of the Group Experience. Brandon, VT: Safer Society Press.

Scharfe, E., \& Bartholomew, K. (1994). Reliability and Stability of Adult Attachment Patterns. Personal Relationships, 1, 23-43.

https://doi.org/10.1111/j.1475-6811.1994.tb00053.x 
Taft, C., Murphy, C., King, D., Musser, P., \& DeDeyn, J. (2003). Process and Treatment Adherence Factors in Group Cognitive-Behavioral Therapy for Partner Violent Men. Journal of Consulting and Clinical Psychology, 71, 812-820. https://doi.org/10.1037/0022-006X.71.4.812

Tasca, G., Balfour, L., Presniak, M., \& Bissada, H. (2012). Outcomes of Specific Interpersonal Problems for Binge Eating Disorder: Comparing Group Psychodynamic Interpersonal Psychotherapy and Group Cognitive Behavioral Therapy. International Journal of Group Psychotherapy, 62, 197-218. https://doi.org/10.1521/ijgp.2012.62.2.197

Tasca, G., Balfour, L., Ritchie, K., \& Bissada, H. (2007). Change in Attachment Anxiety Is Associated with Improved Depression among Women with Binge Eating Disorder. Psychotherapy, 44, 423-433. https://doi.org/10.1037/0033-3204.44.4.423

Tasca, G., Illing, V., Joyce, A., \& Ogrodniczuk, J. (2009). Three-Level Multilevel Growth Models for Nested Change Data: A Guide for Group Treatment Researchers. Psychotherapy Research, 19, 453-461. https://doi.org/10.1080/10503300902933188

Ward, T., Hudson, S., Marshall, W., \& Siegert, R. (1995). Attachment Style and Intimacy Deficits in Sexual Offenders: A Theoretical Framework. Sexual Abuse, 7, 317-335. https://doi.org/10.1177/107906329500700407

Yalom, I., \& Leszcz, M. (2020). The Theory and Practice of Group Psychotherapy. New York: Basic Books.

Yates, P., Prescott, D., \& Ward, T. (2010). Applying the Good Lives and Self-Regulation Models to Sex Offender Treatment: A Practical Guide for Clinicians. Brandon, VT: Safer Society Press.

Yoder, J. Grady, M., Brown, A., \& Dillard, R. (2019). Criminogenic Needs as Intervening Mechanisms in the Relation between Insecure Attachments and Youth Sexual Violence. Sexual Abuse, 32, 247-272. https://doi.org/10.1177/1079063218821108 